\title{
Blood pressure responses after resistance exercise session in women living with human immunodeficiency virus/acquired immunodeficiency syndrome
}

\author{
Wagner Jorge Ribeiro Domingues ${ }^{1, *}$, Vanessa Cristina Nogueiraa', Dayane Cristina de Souza' ${ }^{2}$, Antonio Henrique Germano-Soares ${ }^{3}$, \\ Raphael Ritti-Dias ${ }^{4}$, Ademar Avelar ${ }^{2}$
}

'Physical Education and Sport Center, Londrina State University, Londrina, Parana, Brazil

${ }^{2}$ Department of Physical Education, State University of Maringa, Maringa, Brazil

${ }^{3}$ School of Physical Education, University of Pernambuco, Pernambuco, Brazil

${ }^{4}$ Nove de Julho University - UNINOVE, São Paulo, Brazil

The aim of this study was to verify blood pressure (BP) responses after a single resistance exercise session in women with human immunodeficiency virus/acquired immunodeficiency syndrome (HIV/AIDS). Twelve patients underwent a resisted exercise session. BP, heart rate, and rate pressure product were evaluated before and during $120 \mathrm{~min}$ after the session. Mean cardiovascular values before and after the session were similar $(P>0.05)$. Analysis of the individual data revealed that for $120 \mathrm{~min}$ after exercise, 5 and 4 patients presented a reduction in systolic and diastolic BP of $\geq 4 \mathrm{mmHg}$, respectively. The clinical characteristics of the patients appear to influence BP responses after exercise. Individual data showed that some of the HIV + women demonstrated a clinically significant decrease in BP. Although a single resistance exercise session does not decrease BP in women with HIV/AIDS, individual data present heterogeneity and individual characteristics seem to influence BP reduction after a single session of resistance exercises.

Keywords: Blood pressure, Antiretroviral therapy highly active, Exercise, Resistance training, Human immunodeficiency virus

\section{INTRODUCTION}

Human immunodeficiency virus/acquired immunodeficiency syndrome (HIV/AIDS) is associated with opportunistic pathologies due to low activity of the immune system (Raso et al., 2007). Highly active antiretroviral therapy (HAART) is widely recommended for patients with HIV/AIDS as a way to prevent the onset of these pathologies (Chow et al., 2017; Mendicino et al., 2016). However, HAART increases the cardiovascular risk of the patients (Hsue et al., 2009; Lipshultz et al., 2003; Zareba et al., 2005), especially women (Muyanja et al., 2016). In fact, subjects treated with HAART demonstrated increases of $4.6 \mathrm{mmHg}$ in systolic blood pressure (BP) and $4.2 \mathrm{mmHg}$ in diastolic BP, when compared with HIV + patients who did not adhere to the treat- ment (Wilson et al., 2009).

Resistance training has been recommended for individuals living with HIV/AIDS (Grace et al., 2015), as it promotes improvements in muscle function that are highly affected by the disease. In addition to these effects, studies in other populations have shown that a single session of resistance exercise reduces BP in a broad range of conditions (Queiroz et al., 2009; Teixeira et al., 2011). These acute reductions have been considered clinically meaningful, since they predict chronic reductions in BP after a resistance training program (Tibana et al., 2015). However, whether these benefits also occur in women with HIV + is unknown.

The purpose of this study was to investigate the effects of single session of resistance exercise on BP in women living with HIV/ AIDS.

\footnotetext{
${ }^{*}$ Corresponding author: Wagner Jorge Ribeiro Domingues (iD) https://orcid.org/0000-0003-1638-6465

Physical Education Department, Londrina State University, Celso Garcia Cid highway, km 380, University Campus, Londrina, Parana, 86051-990, Brazil Tel: +55-44-3011-4315, Fax: +55-44-3011-4470, E-mail: wagnerfef@gmail.com Received: April 13, 2018 / Accepted: May 28, 2018
}

This is an Open Access article distributed under the terms of the Creative Commons Attribution Non-Commercial License (http://creativecommons.org/licenses/by-nc/4.0/) which permits unrestricted non-commercial use, distribution, and reproduction in any medium, provided the original work is properly cited. 


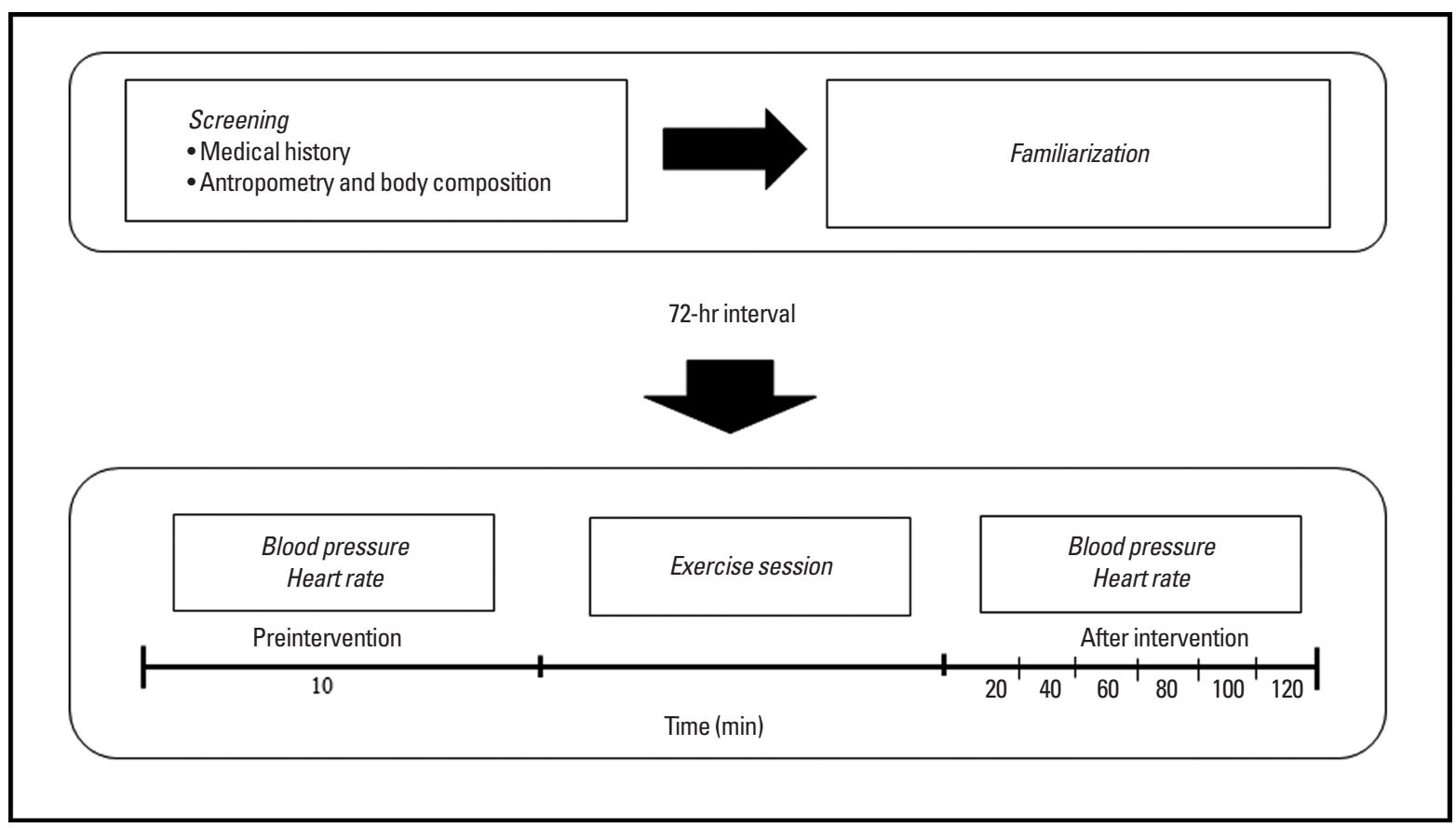

Fig. 1. Experimental protocol.

\section{MATERIALS AND METHODS}

\section{Study design}

The study design is presented in Fig. 1. This study comprised two phases in which the participants performed 6 visits to the laboratory. At first, the participants performed clinical evaluation. After $24 \mathrm{hr}$, each participant underwent familiarization sessions on alternate days. Subsequently, all participants underwent a resistance exercise protocol session. Before and after the experimental session were performed cardiovascular measurements.

\section{Subjects}

Twelve sedentary women living with HIV/AIDS participated in this crossover study. Participants were included if they: (a) > 18 years old, (b) had used HAART for more than 6 months; (c) were in a stable condition and their quantification of HIV viral load had been stable for the previous 6 months; (d) did not smoke; (e) had no musculoskeletal injuries that might affect their ability to perform the exercise protocol; and (f) had not used ergogenic substances in the 6 months prior to the study. The study was conducted according to ethical principles, including the Declaration of Helsinki. Ethical approval was obtained from the Ethics Committee of the State University of Maringa, Brazil (Process $n^{\circ}$ 47513115.0.0000.0104) and each participant provided written consent after familiarization with the study procedures.

\section{Clinical data}

Information on cardiovascular risk, hypertension, and HIV diagnosis were obtained from a medical history prior to the start of the study. Weight and height were obtained using a scale and a stadiometer, from which the body mass index was calculated. The waist circumference and hip circumference were registered according to international guidelines (Lohman et al., 1988). Body fat percentage was estimated by skinfold measurements according to the protocol proposed by (Jackson and Pollock, 1985).

\section{Familiarization}

All patients underwent four-familiarization sessions designed to standardize resistance exercise execution. In these sessions, they performed the following exercises: chest press, leg press $45^{\circ}$, lat pulldown, leg extension, triceps pulley, leg curls, and biceps scott. Each exercise was performed for three sets of 10 repetitions, with 90- and 120-sec intervals between sets and exercises, respectively. Each patient was submitted to the lowest and highest load possible in each exercise in order to perform the anchoring procedures of the OMNI resistance exercise scale (Gearhart et al., 2001). During the final familiarization session, the load corresponding to a rate of perceived exertion between five and seven on the OMNI 
resistance exercise scale was determined for each resistance exercise, as previously described (Lins-Filho et al., 2012).

\section{Experimental session}

After the preintervention procedures, patients performed the resistance exercise protocol. In this protocol, patients performed three sets of 10 repetitions of seven exercises (chest press, $45^{\circ} \mathrm{leg}$ press, lat pulldown, leg extension, triceps pulley extensions, leg curls, and biceps scott curls) with a workload of five to seven on the OMNI resistance exercise scale. Rest intervals of 90 and 120 sec were observed between the sets and exercises, respectively.

After the intervention, patients returned to the laboratory, where they remained seated for $120 \mathrm{~min}$ (postintervention). During this period, BP and heart rate (HR) were measured every $20 \min (20,40,60,80,100$, and 120).

\section{Blood pressure}

The BP was measured using a previously calibrated digital monitor (OMRON DELUXE, HEM 7200 , Brazil). The cuff was adjusted to the circumference of the right arm, 2 to $3 \mathrm{~cm}$ above the cubital fossa at heart level. Measurements were performed in triplicate with a 1-min interval between them. All procedures followed the standardized, national recommendations for BP monitoring (Malachias et al., 2016). HR was measured using an HR monitor (Polar S810, Polar Electro Oy, Finland) and rate pressure product (RPP) was calculated by multiplying systolic BP and $\mathrm{HR}$.

\section{Statistical analysis}

The Gaussian distribution of the data was verified and confirmed by the Shapiro-Wilk test. For the comparison of BP, HR, and RPP before and after exercise one-way analysis of variance for repeated measures was used. To analyze the individual BP responses after

Table 1. Characteristics of participants $(n=12)$

\begin{tabular}{lc}
\hline Variable & Mean \pm SD \\
\hline Age $(\mathrm{yr})$ & $45.75 \pm 11.06$ \\
Weight $(\mathrm{kg})$ & $67.01 \pm 11.32$ \\
Height $(\mathrm{m})$ & $1.55 \pm 0.04$ \\
Body mass index $\left(\mathrm{kg} / \mathrm{m}^{2}\right)$ & $27.75 \pm 3.75$ \\
Waist circumference $(\mathrm{cm})$ & $0.88 \pm 0.04$ \\
Body fat mass $(\%)$ & $38.30 \pm 3.64$ \\
Duration of use HAART $(\mathrm{yr})$ & $130.90 \pm 77.84$ \\
Systolic BP - rest $(\mathrm{mmHg})$ & $123 \pm 21$ \\
Diastolic BP - rest $(\mathrm{mmHg})$ & $83 \pm 7$
\end{tabular}

$\mathrm{SD}$, standard deviation; HAART, highly active antiretroviral therapy; BP, blood pressure. the resistance exercise sessions, we considered a reduction equal or greater than $4 \mathrm{mmHg}$ (Hemmelgarn et al., 2004). The MannWhitney $U$-test was used to compare clinical characteristics among "responder" and "nonresponders" women. The level of significance was $P<0.05$.

\section{RESULTS}

Characteristics of the participants are presented in Table 1. The mean values of systolic and diastolic BP classified participants as normotensive.

Considering the mean values, the systolic BP, diastolic BP, HR, and RPP did not show significant changes before and after a resistance exercise session $(P<0.05)$.

Fig. 2 shows the individual responses of systolic and diastolic
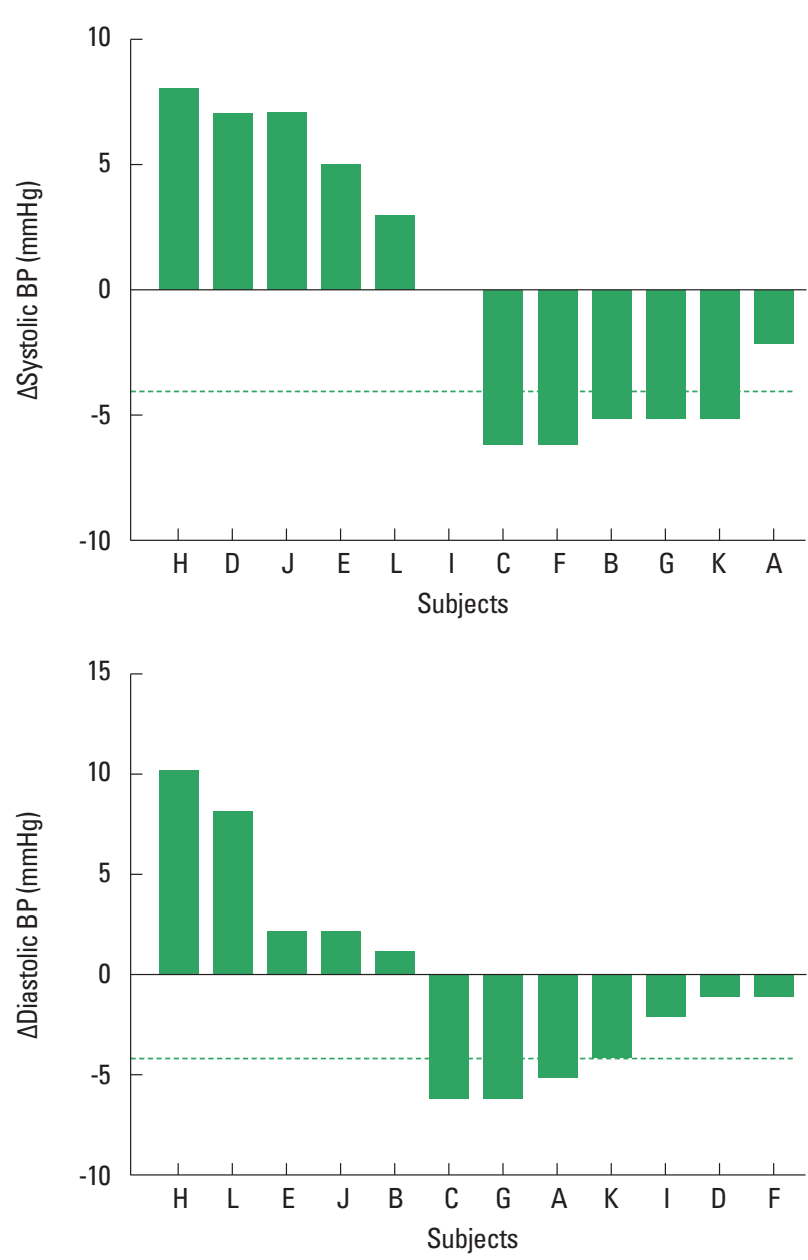

Fig. 2. Individual responses of systolic and diastolic blood pressure (BP) after a resisted exercise session. Responders (reduction in $\mathrm{BP}$ in $\geq 4.0 \mathrm{mmHg}$; dashed line). 
Table 2. Clinical characteristics of patients who presented reduction $\geq 4.0 \mathrm{mmHg}$ before and after the resisted exercise session (SBP, $n=5 ; D B P, n=4)$ compared with patients who did not present this response (SBP, $n=7 ; D B P, n=8$ )

\begin{tabular}{|c|c|c|c|c|c|c|}
\hline \multirow[b]{2}{*}{ Variable } & \multicolumn{2}{|c|}{ SBP } & \multirow[b]{2}{*}{$P$-value } & \multicolumn{2}{|c|}{ DBP } & \multirow[b]{2}{*}{$P$-value } \\
\hline & $\begin{array}{c}\text { Responders } \\
\text { (decreases } \geq 4.0 \mathrm{mmHg} \text { ) }\end{array}$ & Nonresponders & & $\begin{array}{c}\text { Responders } \\
\text { (decreases } \geq 4.0 \mathrm{mmHg} \text { ) }\end{array}$ & Nonresponders & \\
\hline Age (yr) & $47.8 \pm 16.5$ & $44.2 \pm 6.0$ & 0.63 & $51.5 \pm 28.0$ & $40.0 \pm 11.0$ & 0.46 \\
\hline Weight (kg) & $67.7 \pm 16.2$ & $66.4 \pm 7.6$ & 0.87 & $71.7 \pm 12.6$ & $64.6 \pm 10.6$ & 0.36 \\
\hline Height (m) & $1.54 \pm 0.06$ & $1.55 \pm 0.03$ & 0.34 & $1.56 \pm 0.06$ & $1.54 \pm 0.04$ & 0.57 \\
\hline Body mass index $\left(\mathrm{kg} / \mathrm{m}^{2}\right)$ & $28.3 \pm 5.0$ & $27.3 \pm 2.9$ & 0.43 & $29.0 \pm 3.1$ & $27.1 \pm 4.0$ & 0.46 \\
\hline Waist circumference $(\mathrm{cm})$ & $87.8 \pm 10.9$ & $84.4 \pm 3.9$ & 0.34 & $90.9 \pm 8.0$ & $83.3 \pm 6.0$ & 0.10 \\
\hline Waist and hip ratio (cm) & $0.91 \pm 0.02$ & $0.85 \pm 0.03^{*}$ & 0.01 & $0.88 \pm 0.06$ & $0.87 \pm 0.03$ & 0.57 \\
\hline Body fat mass (\%) & $39.4 \pm 3.6$ & $37.4 \pm 3.6$ & 0.34 & $40.1 \pm 2.3$ & $37.3 \pm 3.9$ & 0.28 \\
\hline Duration of use HAART (mo) & $84.0 \pm 162.0$ & $130.9 \pm 144.0$ & 0.75 & $84.0 \pm 36.0$ & $174.0 \pm 126.2^{*}$ & 0.04 \\
\hline CD4/CD8 ratio & $0.45 \pm 0.16$ & $0.82 \pm 0.60$ & 0.20 & $0.30 \pm 0.4$ & $0.72 \pm 0.4^{*}$ & 0.02 \\
\hline Systolic BP (mmHg) & $126 \pm 18$ & $125 \pm 26$ & 0.63 & $133 \pm 15$ & $123 \pm 22$ & 0.15 \\
\hline Diastolic BP (mmHg) & $81 \pm 8$ & $85 \pm 6$ & 0.34 & $87 \pm 4$ & $82 \pm 8$ & 0.46 \\
\hline
\end{tabular}

Values are presented as mean \pm standard deviation.

SBP, systolic blood pressure; DBP, diastolic blood pressuere; HAART, highly active antiretroviral therapy; BP, blood pressure.

${ }^{*} P<0.05$, significant difference.

$\mathrm{BP}$ after the resistance exercise session. Five patients presented a decrease $\geq 4 \mathrm{mmHg}$ in systolic BP and 4 patients in diastolic BP after the exercise session.

Table 2 shows the clinical characteristics of the patients who presented BP decreases $\geq 4.0 \mathrm{mmHg}$ (systolic BP responders, $\mathrm{n}=5$; diastolic BP responders, $\mathrm{n}=4$ ) before and after the exercise session. Responder patients had a higher waist-hip ratio, lower time of HAART use, and lower CD4/CD8 ratio $(P<0.05)$.

\section{DISCUSSION}

The results indicated that there was considerable variability in BP responses after a resistance exercise session among HIV+ women, since some of the subjects presented meaningful decreases in systolic or diastolic BP, while in other patients, cardiovascular parameters were not altered.

Although acute changes in BP have been widely described in the literature (Aprile et al., 2016; Queiroz et al., 2009; Teixeira et al., 2011), high variability in these responses have been reported in normotensive (Costa et al., 2016; Tibana et al., 2015), prehypertensive (Hecksteden et al., 2013), hypertensive (Kiviniemi et al., 2015; Lima et al., 2015; Moreira et al., 2016) individuals. Our findings broaden the current knowledge, showing that this variability also occurs in women with HIV/AIDS. Analysis of the individual responses demonstrated that $42 \%$ and $33 \%$ of the participants presented a clinically relevant reduction in systolic and diastolic BP, respectively. This is similar to a study in patients with peripheral artery disease (Lima et al., 2015) who demonstrated clinically significant reductions of $46 \%$ in systolic BP and $38 \%$ in diastolic BP after resistance exercise. These findings suggest that the responsiveness of BP to resistance exercise occurs in different clinical populations.

In our study, HIV + women who presented reductions $\geq 4$ $\mathrm{mmHg}$ in diastolic BP had a shorter time using HAART, a lower $\mathrm{CD} 4 / \mathrm{CD} 8$ ratio, and higher abdominal obesity. Interestingly, these individuals present a more vulnerable immune system $(\mathrm{CD} 4 / \mathrm{CD} 8$ ratio $<1)$ and are more likely to present atherosclerotic plaque (Serrano-Villar et al., 2014a; Serrano-Villar et al., 2014b). Thus, our findings show for the first time that more vulnerable HIV + women might present greater transient acute reductions in BP after resistance exercise.

From a practical point of view, resistance exercises for HIV/ AIDS patients are recommended because of the benefits to the musculoskeletal system. Recently, BP responses following a single session of exercise have been considered a predictive tool to identify the chronic cardiovascular effects of training (Tibana et al., 2015). Thus, if similar responses occur in women with HIV, our results suggest that women who have been using HAART for less time, present abdominal obesity, and have a low CD4/CD8 ratio are potentially more likely to present chronic reductions in $\mathrm{BP}$ with resistance training.

The present study has some limitations. The lack of a control session (without exercise) is a major limitation and does not allow control for the impact of circadian variation on cardiovascular pa- 
rameters. It also limits the strength of the identification of the individual responses to exercise, and although we performed several measures during the postexercise period, assumptions should be made with caution (Atkinson and Batterham, 2015). The small sample size limited the comparisons between "responders" and "nonresponders." Our results are restricted to normotensive women and whether these results are replicable in men and hypertensive patients needs to be investigated. Finally, we investigated the cardiovascular variables for up to $2 \mathrm{hr}$ after an exercise session. Other studies are encouraged to investigate whether changes are maintained under outpatient conditions.

In conclusion, the results of this study indicated a considerable variability in BP responses after a resistance training session. HIV + women with a higher waist-hip ratio, shorter treatment duration, and lower $\mathrm{CD} 4 / \mathrm{CD} 8$ ratio presented higher acute reductions in systolic and diastolic BP.

\section{CONFLICT OF INTEREST}

No potential conflict of interest relevant to this article was reported.

\section{ACKNOWLEDGMENTS}

This work was supported by the Foundation for Research Support of the State of Amazonas (FAPEAM grant \#062.03159.2014), National Council for Scientific and Technological Development (CNPQ grant \#428555/2016-0) and Araucaria Foundation (grant \#40904.425.36484.26072013).

\section{REFERENCES}

Aprile DC, Oneda B, Gusmão JL, Costa LA, Forjaz CL, Mion D Jr, Tinucci T. Post-exercise hypotension is mediated by a decrease in sympathetic nerve activity in stages 2-3 CKD. Am J Nephrol 2016;43:206-212.

Atkinson G, Batterham AM. True and false interindividual differences in the physiological response to an intervention. Exp Physiol 2015;100: $577-588$.

Chow FC, Li Y, Hu Y, Chan J, Wang H, Xu W, Price RW, Sorond FA, Li T. Relationship between HIV infection, antiretroviral therapy, inflammatory markers, and cerebrovascular endothelial function among adults in urban China. J Acquir Immune Defic Syndr 2017;74:339-346.

Costa EC, Dantas TC, de Farias Junior LF, Frazão DT, Prestes J, Moreira

SR, Ritti-Dias RM, Tibana RA, Duhamel TA. Inter- and intra-individual analysis of post-exercise hypotension following a single bout of high-intensity interval exercise and continuous exercise: a pilot study. Int J Sports Med 2016;37:1038-1043.

Gearhart RE, Goss FL, Lagally KM, Jakicic JM, Gallagher J, Robertson RJ. Standardized scaling procedures for rating perceived exertion during resistance exercise. J Strength Cond Res 2001;15:320-325.

Grace JM, Semple SJ, Combrink S. Exercise therapy for human immunodeficiency virus/AIDS patients: Guidelines for clinical exercise therapists. J Exerc Sci Fit 2015;13:49-56.

Hecksteden A, Grütters T, Meyer T. Association between postexercise hypotension and long-term training-induced blood pressure reduction: a pilot study. Clin J Sport Med 2013;23:58-63.

Hemmelgarn BR, Zarnke KB, Campbell NR, Feldman RD, McKay DW, McAlister FA, Khan N, Schiffrin EL, Myers MG, Bolli P, Honos G, Lebel M, Levine M, Padwal R; Canadian Hypertension Education Program, Evidence-Based Recommendations Task Force. The 2004 Canadian Hypertension Education Program recommendations for the management of hypertension: Part I--Blood pressure measurement, diagnosis and assessment of risk. Can J Cardiol 2004;20:31-40.

Hsue PY, Hunt PW, Schnell A, Kalapus SC, Hoh R, Ganz P, Martin JN, Deeks SG. Role of viral replication, antiretroviral therapy, and immunodeficiency in HIV-associated atherosclerosis. AIDS 2009;23:10591067.

Jackson AS, Pollock ML. Practical assessment of body composition. Phys Sportsmed 1985;13:76-90.

Kiviniemi AM, Hautala AJ, Karjalainen JJ, Piira OP, Lepojärvi S, Ukkola O, Huikuri HV, Tulppo MP. Acute post-exercise change in blood pressure and exercise training response in patients with coronary artery disease. Front Physiol 2015;5:526.

Lima AH, Miranda AS, Correia MA, Soares AH, Cucato GG, Sobral Filho DC, Gomes SL, Ritti-Dias RM. Individual blood pressure responses to walking and resistance exercise in peripheral artery disease patients: Are the mean values describing what is happening? J Vasc Nurs 2015; 33:150-156

Lins-Filho Ode L, Robertson RJ, Farah BQ, Rodrigues SL, Cyrino ES, Ritti-Dias RM. Effects of exercise intensity on rating of perceived exertion during a multiple-set resistance exercise session. J Strength Cond Res 2012;26:466-472.

Lipshultz SE, Fisher SD, Lai WW, Miller TL. Cardiovascular risk factors, monitoring, and therapy for HIV-infected patients. AIDS 2003;17 Suppl 1:S96-122.

Lohman TG, Roche AF, Martorell R. Anthropometric standardization reference manual. Champaign (IL): Human Kinetics; 1998.

Malachias MV, Barbosa EC, Martim JF, Rosito GB, Toledo JY, Passarelli O Jr. 7th Brazilian guideline of arterial hypertension: chapter 14 - hypertensive crisis. Arq Bras Cardiol 2016;107(3 Suppl 3):79-83. 
Mendicino CC, Braga LP, Pádua CA, Guimarães MD. High incidence of hypertriglyceridemia in a Brazilian cohort of people living with HIV/ AIDS undergoing antiretroviral treatment in Belo Horizonte, 20012010. Rev Soc Bras Med Trop 2016;49:758-762.

Moreira SR, Cucato GG, Terra DF, Ritti-Dias RM. Acute blood pressure changes are related to chronic effects of resistance exercise in medicated hypertensives elderly women. Clin Physiol Funct Imaging 2016;36: 242-248.

Muyanja D, Muzoora C, Muyingo A, Muyindike W, Siedner MJ. High prevalence of metabolic syndrome and cardiovascular disease risk among people with HIV on stable ART in Southwestern Uganda. AIDS Patient Care STDS 2016;30:4-10.

Queiroz AC, Gagliardi JF, Forjaz CL, Rezk CC. Clinic and ambulatory blood pressure responses after resistance exercise. J Strength Cond Res 2009;23:571-578.

Raso V, Casseb JS, Duarte AJ, Greve JM. A brief review on physical exercise and HIV/AIDS. R bras Ci e Mov 2007;15:115-126.

Serrano-Villar S, Moreno S, Fuentes-Ferrer M, Sánchez-Marcos C, Avila M, Sainz T, de Villar NG, Fernández-Cruz A, Estrada V. The CD4:CD8 ratio is associated with markers of age-associated disease in virally suppressed HIV-infected patients with immunological recovery. HIV
Med 2014a;15:40-49.

Serrano-Villar S, Sainz T, Lee SA, Hunt PW, Sinclair E, Shacklett BL, Ferre AL, Hayes TL, Somsouk M, Hsue PY, Van Natta ML, Meinert CL, Lederman MM, Hatano H, Jain V, Huang Y, Hecht FM, Martin JN, McCune JM, Moreno S, Deeks SG. HIV-infected individuals with low CD4/CD8 ratio despite effective antiretroviral therapy exhibit altered $\mathrm{T}$ cell subsets, heightened CD8+ T cell activation, and increased risk of non-AIDS morbidity and mortality. PLoS Pathog 2014b;10:e1004078.

Teixeira L, Ritti-Dias RM, Tinucci T, Mion Júnior D, Forjaz CL. Post-concurrent exercise hemodynamics and cardiac autonomic modulation. Eur J Appl Physiol 2011;111:2069-2078.

Tibana RA, de Sousa NM, da Cunha Nascimento D, Pereira GB, Thomas SG, Balsamo S, Simoes HG, Prestes J. Correlation between acute and chronic 24-hour blood pressure response to resistance training in adult women. Int J Sports Med 2015;36:82-89.

Wilson SL, Scullard G, Fidler SJ, Weber JN, Poulter NR. Effects of HIV status and antiretroviral therapy on blood pressure. HIV Med 2009;10: 388-394.

Zareba KM, Miller TL, Lipshultz SE. Cardiovascular disease and toxicities related to HIV infection and its therapies. Expert Opin Drug Saf 2005; 4:1017-1025. 